about 71,000 doctors in India, 25 per million in rural areas and 800 per million in urban areas, while the present 55 medical colleges have an annual intake of 5,000 and train about 2,800 graduates each year. The position regarding women doctors is particularly unsatisfactory. It is suggested that it is not suitable to increase the number of medical colleges at present, but that the resources of the Plan could be more profitably used in raising the standard of teaching, providing more equipment and space in the hospitals and laboratories and increasing the staff of qualified teachers in existing institutions. The total allocation of Rs.300 crores is regarded as inadequate, and besides a determined effort to eliminate the adulteration of food, a bolder policy in regard to water supply and sanitation is urged, and expansion of the existing scheme for eradication of endemic goitre by the supply of iodinated salt is recommended to cover the whole of the endemic belt. The public health laboratories envisaged should be provided with free diagnostic services for the public.

\section{Information on Translations}

A NEW international information office has been jointly established by Euratom, the U.S. Atomic Energy Commission and the U.K. Atomic Energy Authority in Brussels. Called 'Transatom', it is intended to act as a clearing house for information on the translations of nuclear literature available from a variety of organizations. It publishes monthly the Transatom Bulletin, which lists in the style of Nuclear Science Abstracts translations at present available of articles, with source and price. It also lists forthcoming translations as well as translations of whole journals. In addition to this service, 'Transatom' is assembling a master file of translations of interest. This file may be consulted by subscribers to the Bulletin. The first issue of the Bulletin is dated December 1960 (Pp. 80.50 francs ; 1 dollar. Bruxelles: Euratom, Transatom Service, 51 rue Belliard, 1960). The majority of the translations listed are from Russian and Japanese journals, and the language of the translation is English, French or German. Further information may be obtained from Euratom, Transatom Service, 51 rue Belliard, Brussels.

\section{International Natural History Research}

Young naturalists all over Europe have been carrying out a survey of the arrival and departure of the swift and the flowering time of the wood anemone. Their report for 1959 has been issued by the International Youth Federation for the Study and Conservation of Nature. The first swift was reported in Holland on April 18, and the 'last first' in Finland on June 7. On the return migration the swifts disappear from the more southerly breeding localities before they have left those in Scandinavia. The first wood anemone came into bloom in Holland on March 19, and the 'last first' in mid-Finland on May 18. Many Nature clubs in Britain are associated with the Federation through the British Co-ordinating Group, but there is no reason why young naturalists in any society should not participate. The programme for 1961 will follow the plan as used in previous years. Introductory notes and duplicated recording sheets will be available very soon and the work will begin in the early spring. Recording for the wood anemone will be over by about the beginning of April, but recording for the swift will continue until the end of the summer. For the swift, the dates for the arrival of the first individual and the main flock will be required, details about nesting sites, numbers of young birds in selected nests and also the dates at which the birds left the area in the autumn. For the wood anemone, information will be required about the habitat, abundance of plants at a given locality, details of the phenology and also counts of the number of petals on individuals in a random sample. Information and recording sheets will be available from the secretary of the Naturalist, Derek S. Davis, 56 Altmore Avenue, East Ham, London, E.6.

\section{The National Art Gallery and Dominion Museum, New Zealand}

THE report of the Board of Trustees of the National Art Gallery and Dominion Museum for the year ended March 1960 discloses a year of activity in many directions (Pp. 30. (H. 21.) Wellington : Government Printer, 1960). Temporary exhibitions included an unusual one of Czechoslovakian Truka puppets. The re-appointment of an educational officer has proved of great value to this side of the gallery work. In the Museum section some valuable field work has been undertaken including natural history investigations in twelve outlying islands in Cook Strait and the recording of Mrori occupation sites in the Wellington District. An impressive list of publications by the staff is an indication of the value of research as one of the functions of a museum.

\section{Coronary Artery of the Portuguese East African}

MyocaRdial infarction is generally recognized to be the consequence of thrombosis in a diseased coronary artery. While not all diseased arteries promote thrombosis, the frequent association of thrombosis and coronary disease has led to the view that perhaps an understanding of the factors promoting disease of the coronary artery may assist in preventing the high incidence of myocardial infarction in the Western world. In searching for æetiological factors, attention has been focused largely on the age group in which coronary disease is most likely to declare itself clinically. Equally important, but less well known, is the observation that the coronary artery is unique in that regressive changes are initiated early in life, and even within a month after birth. Some of these regressive changes, if accentuated, are unmistakably similar to those which have been described in advanced sclerosis, with and without atherosis of the coronary artery.

During the past twenty-four years, several reports have directed attention to the rarity of coronary thrombosis in the indigenous peoples of different parts of Africa. While advanced coronary disease has been described in the African, it is believed that the disease is less common, milder in character and declares itself later than in the white races of Europe and the United States of America. In view of this marked difference in susceptibility to coronary artery disease of white people and Africans, and of the expressed opinion that the regressive changes occurring in the coronary artery soon after birth may be linked to the pathogenesis of coronary disease, Joseph Gillman, Christine Gilbert and Manuel D. Prates have considered it desirable to examine the coronary arteries at different periods of life of an African population in which coronary artery disease 